Proceedings of the 2011 Winter Simulation Conference

S. Jain, R.R. Creasey, J. Himmelspach, K.P. White, and M. Fu, eds.

\title{
DISCRETE EVENT SIMULATION AS DIDACTIC SUPPORT TO THE TEACHING OF TELECOMMUNICATIONS SYSTEMS: APPLICATIONS IN DIGITAL TELEPHONY
}

\author{
Thiago Miranda Paravidino da Silva \\ João José de Assis Rangel \\ Instituto Federal Fluminense \\ 273 Dr. Siqueira st, Pq. Dom Bosco \\ Campos dos Goytacazes, RJ, 28030-130, BRAZIL
}

\begin{abstract}
The development of telecommunications in Brazil demands increasingly skilled professionals. Professional training in this area is mainly acquired in the courses of technical and technological training. In the teaching of telecommunications, an alternative to the rapid technological progress and the cost of equipment for laboratory practice is the use of didactic simulators. Animation models were developed to represent concepts in digital telephony, specifically in time-division multiplexing, demultiplexing and switching time. Visualization tests were made with multimedia resource for the teacher in the classroom and with personal computers for each student in the computer lab. The models were adequate as an additional tool in teaching telecommunications and as a complement of the laboratory practice in the discipline of telephony. We noticed the potential of discrete simulation software to make animation models for technical and technological education in other subjects in the course of telecommunications.
\end{abstract}

\section{INTRODUCTION}

After the development of telecommunications in Brazil, this sector has had strong investment and technological progress by the operators. These operate in various segments, especially the segment of fixed and mobile telephony, through the modernization of the network and digitization of the equipment involved in the system. As a consequence of this inflow of investments and technological development, there were an increasing number of users and a consequent need for specialized, technical manpower. The training of skilled technicians is achieved through training of the company or courses of technical and technological training.

There are challenges of education to be taken into account in the technological area, and as challenges, we consider first, the difficulty as a reflection of the speed of technological expansion. It means that if, some time ago, one taught analog cellular telephony, today one teaches the digital. It is to say that a teaching kit may soon become obsolete concerning this technological advance. Second, when it comes to telecommunications, the cost of equipment and systems for hands-on practice prevents a close contact of students with certain technologies. Thus, the concepts are worked out only from a theoretical or through visits to companies of interest. Third, in the area of telecommunications, it is possible to use software for simulation purposes in some areas; however, many of these require a license to use, limiting the use by the student only to the academic environment.

These facts drive the search for new resources to improve and enhance the classroom and laboratory. Among the resources available to encourage learning, the computer is the best representation, as it offers a wide range of possibilities and ease of access, especially within institutions of technical and technological education. According to Cardoso (2006), information and communication technologies are 


\section{Silva and Rangel}

becoming more prevalent in education, providing interactivity to the educational process and providing a closer link between the student and learning.

An alternative to the obsolescence of learning kits, to the cost of equipment / systems and to the access to specific, proprietary simulators is the use of a simulation environment for building models of different systems. Some software simulators commonly used in Brazil are ARENA, Promodel, and Simul8. White Jr. and Ingalls (2009) define simulation as an imitation of the operations of a process or system over time. As a teaching resource, the simulator must allow simulating telecommunications systems and update them as needed. It also serves as a tool for improving student's knowledge acquired in classroom.

The acquisition of simulation software is expensive; however, acquisition costs can be diluted as it allows the development of various models. In addition, some simulation environments have a student version, which allows the construction and use of virtual models outside the academic environment. This is not possible with the use of a simulator of a specific system, as they are commonly used to demonstrate only a well-defined situation, not allowing changes or creation of new models.

The construction of virtual simulation models with tools, and to the scope of the student, proves to be interesting in the educational context, especially if this model can absorb, for example, the new parameters of an updated system. In simulation environments, adjustments can be made with only minor configuration changes to the model, rendering it more convenient to what we intend to teach in situations of changing parameters of a real more modern system.

Considering the above, the main objective of this work is to develop discrete simulation models to use as a didactic computational resource for teaching computer telecommunications. The main focus will be the concepts covered in digital telephony, where the student will be able to see through animation aspects of the system that are presented only in a theoretical way.

\section{SIMULATION AS A TEACHING RESOURCE ON EDUCATION AND TRAINING}

Cardoso (2006) explains that the effort of teaching and learning attracts education scholars for the restructuring and modernization of the courses in order to adapt them to new methodologies or steady them to the existing ones. The goal is to prepare professionals capable to meet the challenges posed by a technological career.

Goldsman (2007) explains the importance of computer simulation to improve the skills of students, exemplifying his study with the application of simulation as a teaching resource at high school level, specifically in the study of mathematics.

Rangel and Teixeira (2010) explain that in Brazil the use of computers as a teaching resource has become a reality since the 90 's due to factors such as technological development, government policies, spread of the Internet and the emergence of educational software. The work of these researchers proposed the analysis of the use of software ARENA in the development of simulation, aiming to teach Physics in high schools.

According to Silva, Pinto and Subramanian (2007), simulation software enables the learning interaction and acts as a facilitator of the teaching-learning process, having as the main advantage the feature animation. They also emphasize that educational software allows a greater readability by students concerning the concepts that should be developed. These researchers based their work proposing the use of simulation, specifically ARENA software, as a didactic resource to the teaching of concepts in Production Engineering.

Kincaid and Westerlund (2009) say that the simulation provides a safe environment that allows training in cognitive and psychomotor tasks, allowing increasing the skills of workforce without the risks of an accident or human error. They base their study citing applications such as simulation training in several areas.

Barradas et al. (2009) demonstrate in their work the importance of using simulation with optimization in areas other than those traditionally studied, and focus their research on the application of simulation in 


\section{Silva and Rangel}

telecommunications. They conclude that the developed model got approval in relation to the real problem, moreover, they point out that the results were considered valid by experts.

Referring specifically to the simulation applied to the teaching of systems of telecommunications, the most obvious contribution in this area of knowledge is the possibility of animation actions. This is justified because some contents are covered only in a theoretical and static way, hindering the understanding and full comprehension of the system under study. Therefore, we expect a positive contribution in technical training for telecommunications students, who at some point in their careers will use the knowledge acquired in the classroom in the performance of their professional activities within the company.

\section{DESCRIPTION OF THE SYSTEM}

The system being simulated consists of digitized channels of $64 \mathrm{kbps}$ each, which should be grouped conveniently. When referring to the junction between switchboards, we no longer refer to a single telephone channel. We refer to a set of channels that will form the link transmission, aiming higher volumes of traffic through multiplexer systems.

Multiplexed transmission systems follow standardized hierarchies, as explained in Neto and Neto (2002). In Brazil, the European standard is adopted, but there are other patterns of transmission. However, these patterns will not be a focus in this work. Table 1 shows the transmission rates involved along the hierarchy addressed. It is also possible to observe the quantitative of multiplexed channels at each stage of the system.

Table 1: 30-Channel Digital Hierarchy (Adapted from Bernal and Falbriard (2002))

\begin{tabular}{llll}
\hline Order & $\begin{array}{l}\text { Name of the Digital } \\
\text { Signal }\end{array}$ & Bandwidth & $\begin{array}{l}\text { Number of Channels } \\
\text { of 64 kbps }\end{array}$ \\
\hline 1 & E1 & $2048 \mathrm{kbps}$ & 30 \\
2 & E2 & $8448 \mathrm{kbps}$ & 120 \\
3 & E3 & $34368 \mathrm{kbps}$ & 480 \\
4 & E4 & $139264 \mathrm{kbps}$ & 1920 \\
5 & E5 & $565000 \mathrm{kbps}$ & 7680 \\
\hline
\end{tabular}

Figure 1 shows a representative scheme for the formation of the transmission link of $2 \mathrm{Mbps}$, with 30 telephone channels at $64 \mathrm{kbps}$. The next stages are also represented in the figure through the formation of links of $8 \mathrm{Mbps}, 34 \mathrm{Mbps}$ and $140 \mathrm{Mbps}$ respectively.

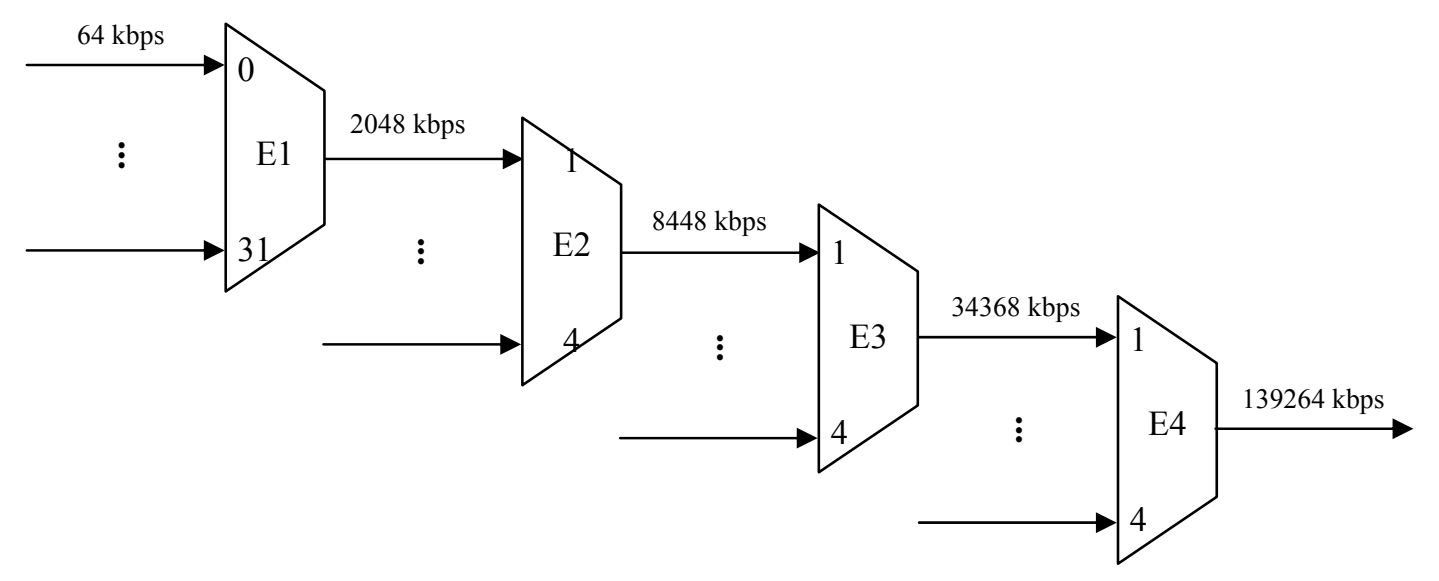

Figure 1: Assembling the 30-Channel Digital Hierarchy (Adapted from Bernal and Falbriard (2002)) 


\section{Silva and Rangel}

Besides the 30 channels, two channels should be considered for signaling, occupying position 0 and position 16 of the set of 32 channels to be transported. These channels receive information of signaling according to its location within the group.

One must use digital multiplexing resources, where each channel will occupy a position in time (time slot) within the link, so that the 32 telephone channels can be grouped under a link of 2 Mbps. On reception of the system, these channels should be delivered to their destination. The reverse process or demultiplexing is done in order to do that.

Once allocated within the link, one can change the positions among the various channels. For this, the technique of switching time is used, which through memory structure and addressing allows changing the position among the channels. Thus, for example, a source can communicate with any destination according to the need of transmission.

\section{SIMULATION MODEL}

The simulation model must represent the basic formation of the E1 link with the insertion of 30 telephone channels plus 2 channels of signals in their respective positions. Aspects such as multiplexing, demultiplexing, switching time should also be considered by the model. In a second step, the formation of the superior links E2, E3 and E4 should be represented. One must first design the conceptual model of the system, so that the simulation model is developed satisfactorily.

According to explanations of Pidd (2004) and Carson (2004), conceptual modeling techniques facilitate the capture, display and interpretation of system elements. Thus, it is possible to have an orderly progression of the study, where all functions and variables available in the real system and the interconnections and rules will be represented by sketch.

The representation of simulation models covered by this work will be done in IDEF-SIM. According to Montevechi et al. (2010), IDEF-SIM is a technique used for initial graphical representation of the system being modeled and for documenting the logic used in the simulation model. Nunes and Rangel (2009) highlight the simplification of the model and the documentation with no ambiguity as benefits of IDEF-SIM. That contributes to the construction of simulation models and consequently to animation model, appropriate to the theoretical needs of the teaching of telecommunications.

\subsection{Formation of the Basic Link E1}

The conceptual model represented in Figure 2 shows the first stage of multiplexing, where 32 channels, numbered from $\mathrm{C} 1$ to $\mathrm{C} 32$ will share the same link of 2 Mbps. These channels will be allocated on the link using the technique TDM (time division multiplexing) and, as said before, the positions 0 and 16 are reserved for signaling channels. At the reception, the demultiplexer performs counter function, separating the channels and allocating them to their destination.

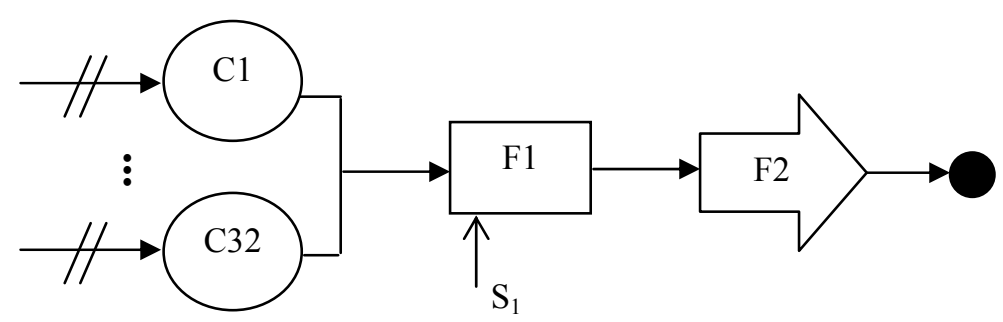

Figure 2: Conceptual model of formation of link E1 


\section{Silva and Rangel}

\subsection{Formation of the Link in the Advanced Stages}

In systems that require larger capacity of canalization available, it is necessary to multiplex 4 basic links of $2 \mathrm{Mbps}$ or E1 link, in a higher stage. Then, a link is formed with higher speed and greater number of channels. This link is called E2. For high-capacity systems, the process is repeated by grouping 4 E2 links to form an E3 link. It is still possible to gather a larger number of channel multiplexing in higher stages, thus getting the links E4 and E5, which will be available for media transmission in high speed, typically fiber optic or digital radio systems.

Figure 3 represents the conceptual model of the formation of high-capacity links in the upper stages. It only shows the formation of E2 link by multiplexing 4 E1 links (E11 to E14). However, the conceptual model for the formation of links E3, E4 and E5 is the same, changing only the configuration parameters for them. These should be different from those used in the configuration of the simulation of the formation of link E1 and E2.

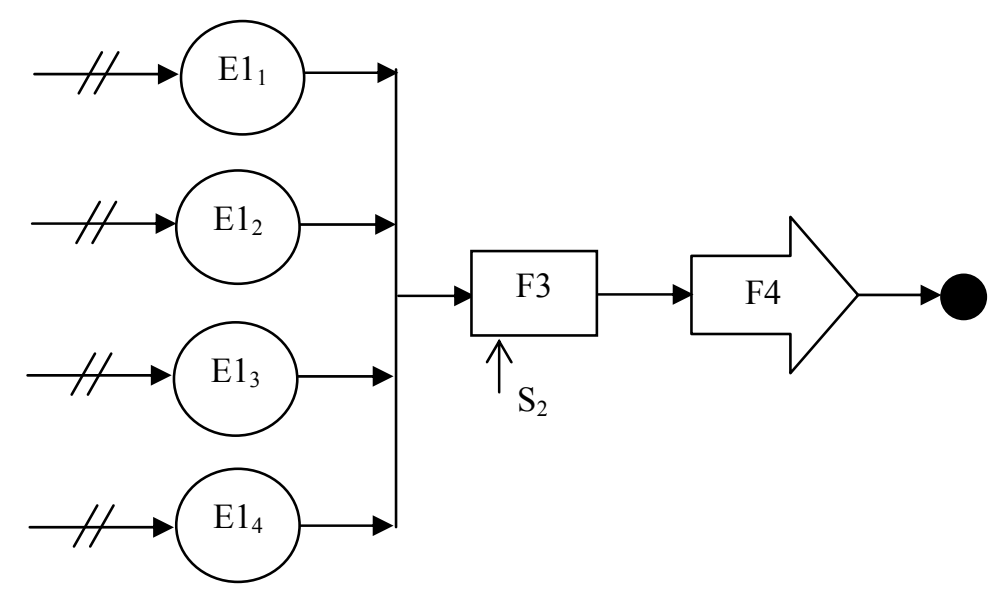

Figure 3: Conceptual model of formation of E2 Link

Table 2 shows the configuration parameters used in simulation models proposed for this work.

Table 2 - Configuration parameters of the simulation model

\begin{tabular}{lll}
\hline Item & Description & Parameters \\
\hline $\mathrm{C} 1$ to C32 & Channels of 64 kbps & Constant; 1 at a time \\
$\mathrm{E}_{1}$ to E1 & Links of 2 Mbps & Constant; 1 at a time \\
$\mathrm{S}_{1}$ & Synchronization in stage 1 & Quantity: 1 \\
$\mathrm{S}_{2}$ & Synchronization in stage 2 & Quantity: 1 \\
$\mathrm{F}_{1}$ & Multiplexing in stage 1 & Transportation: 1; velocity: 10 \\
$\mathrm{F}_{2}$ & Multiplexing in stage 2 & Transportation: 1; velocity: 10 \\
$\mathrm{F}_{3}$ & Transmission line E1 & Track: 1; Length: 20; Velocity: 5 \\
$\mathrm{F}_{4}$ & Transmission line E2 & Track: 1; Length: 20; Velocity: 5 \\
\hline
\end{tabular}

\section{EXPERIMENTS FOR EDUCATIONAL SUPPORT}

The animation models for three issues addressed specifically in the discipline of telephony and focused on digital telephony will be presented in this section. These models are multiplexing by time division, demultiplexing and switching time. These three approaches were chosen because one of the authors of this paper teaches the Telecommunications technician course at an institution of technical and technological education. This will allow the validation and testing of models. 


\section{Silva and Rangel}

To create models of simulation and animation models, we use the software ARENA 12. It is worth mentioning that this software allows the construction of simulation models for discrete events, according to Kelton (2007). Banks et al. (2010) define discrete event as the one in which change of state occurs at certain points of time. This definition is appropriate to the nature of the information signal of the systems under study, which in its basic structure is called bytes, or digital signal. In the classical definition, bytes are those that have defined states over time.

The concepts discussed should theoretically be translated into visual actions, aiming to answer possible questions of content applied only in the traditional way.

The models were developed using a computer type notebook with the following features: Windows XP SP2, Intel Celeron M processor, LCD screen 14.1 inches and screen proportions of $16 / 9$ (widescreen), ROM memory of 512 MB DDR2 533 Mhz, 80 GB SATA hard drive and DVD-RW drive. As an added feature, USB optical mouse was used to assist in development of the models proposed here.

After the construction of the three models in this paper, a visualization test was made in the classroom. We used a standard television 29 inches of standard tube and proportions of screen $4 / 3$, attached to S-video connector of the notebook used for animation development. In this case, the objective was to evaluate the use of models in class, with the use of multimedia resource in a traditional classroom, without the use of personal computers for students.

Visualization tests were also performed in laboratories. These had desktop computers with monitors default type CRC of 17 inches and proportions screen of 4 / 3. In a real classroom environment, we would have one computer for each student. In this case, it was possible to evaluate the use of models in computer labs.

A third test was performed using visualization desktop computer with 21.5-inch wide screen display. The intent of this test was to evaluate the use of animation models in computer labs with computers that have the most modern monitors. It was not possible to evaluate the models in the classroom with multimedia resources and wide screen TV.

\subsection{Multiplexing by Time Division}

Figure 4 shows an animation of experiment 1 or multiplexing where, through animation resources of the ARENA, it was possible to demonstrate the process of sampling the channels to be transmitted and the proper allocation of these in the link.

The real TDM system works multiplexing 32 channels in a single means of transmission, but for didactic purposes, we built a model of 5-channel multiplexer represented by entities differentiated by color and name, it means from green C_01 to red C_05, aiming to improve the perception of the student in relation to the concepts explored in the classroom.

It is hoped that this model can represent the sampling of individual channels, the allocation of samples in the means of transmission, the speed difference between the individual channels and the multiplexed link.

\subsection{Multiplexing and Demultiplexing}

After the multiplexing shown in the previous section, it is understandable that the student thinks that the multiplexed link has a destination. Therefore, we proposed the full process model from the multiplexed transmission to the reception. Thus, each channel must be separated, or demultiplexed, and designed to its destination.

The purpose of this model is to show how a multiplexed channel is separated from link and destined to a receptor. Figure 5 shows the whole process and allows us to observe that the channels occupy the same position in both transmission and reception. This means that the origin "a" exclusively communicates with the destination "a," not being able to communicate with any destination, as needed. 


\section{Silva and Rangel}

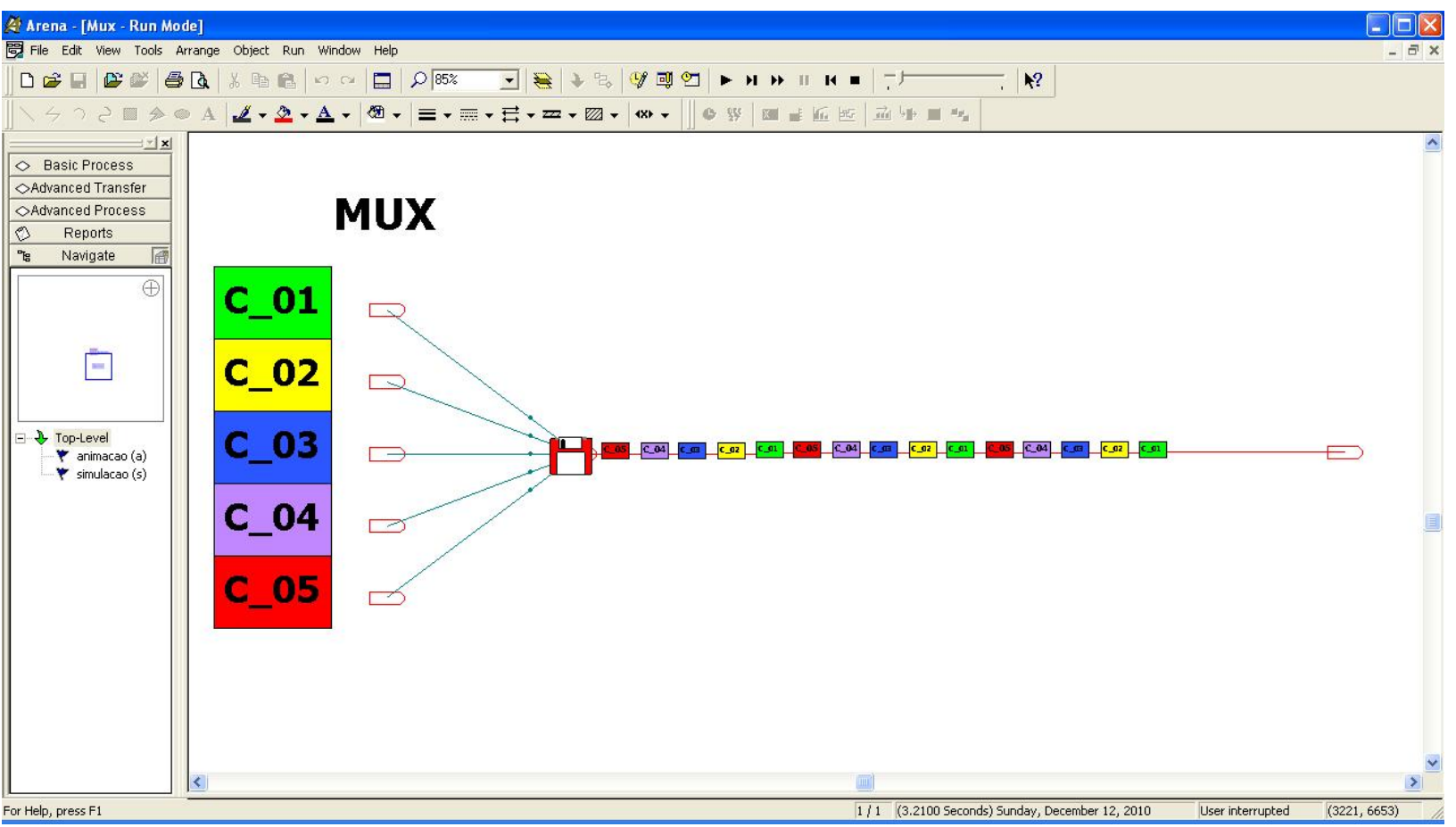

Figure 4: Multiplexer by time division in ARENA animation

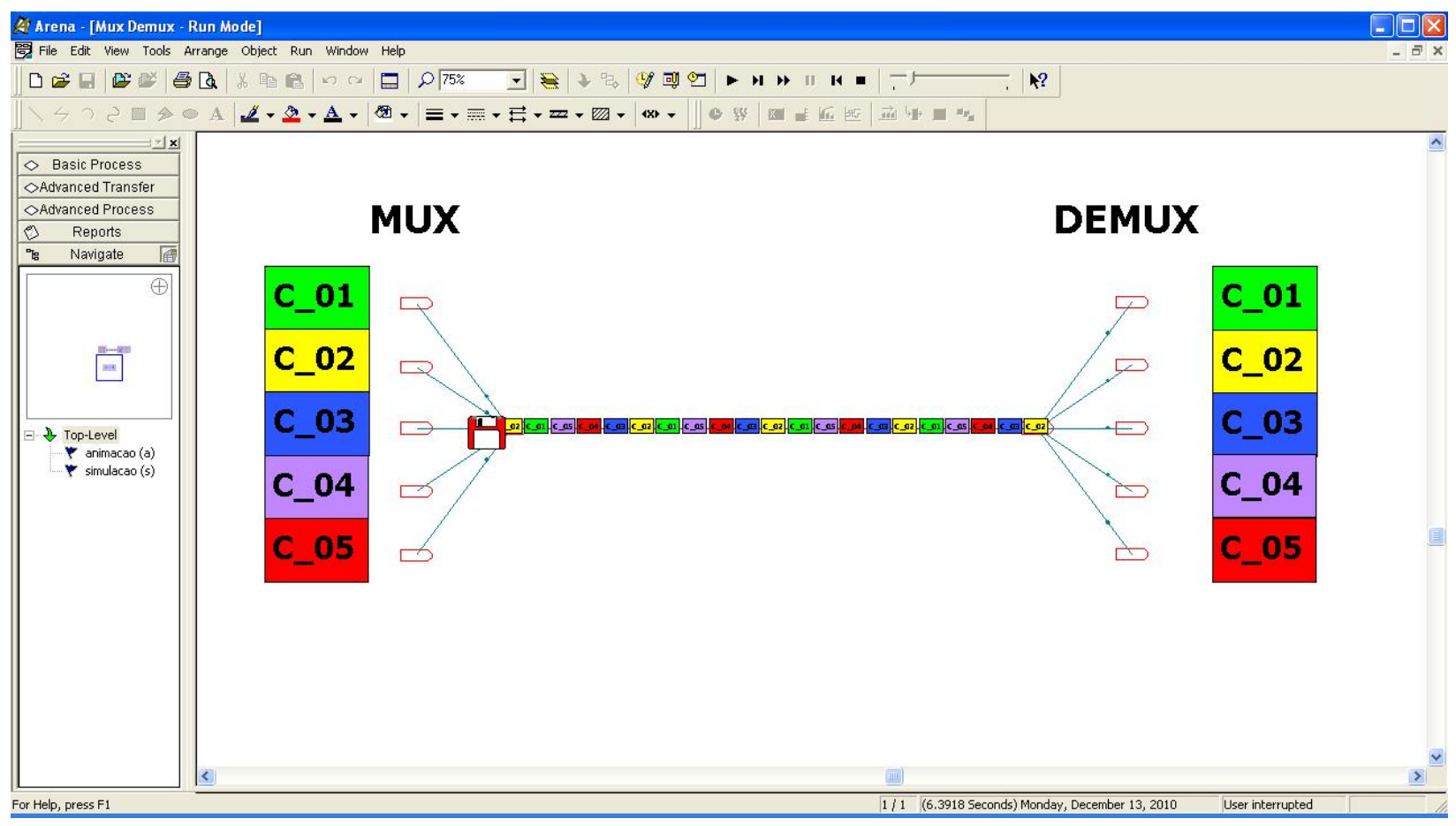

Figure 5: Mux / Demux in ARENA animation 


\section{Silva and Rangel}

\subsection{Switching Time}

The construction of the animation model to represent the switching time was proposed considering the difficulties of communication between a source and any destination, mentioned in the previous item. It was also considered the questioning character of the student in the learning process.

The main objective of this model is to answer the most common question when teaching the discipline of telephony and addresses the subject developed in items 5.1 and 5.2: "How can a subscriber communicate with any other subscriber of his choice?" The following explanations try to clarify it.

Utilizing the same elements used to represent the multiplexer and demultiplexer, we could demonstrate, with the help of animation, how the bytes that represent the information trafficked on each channel can change position within the link after several channels have been multiplexed.

In its traditional definition, switching is the possibility of any source to communicate with any destination according to the need for transmission. The student can see the process of writing and reading of memory used for switching time. He understands that the channels are written in order of arrival and read in the order necessary for the switching to occur.

Figure 6 shows the example in relation to channel 1, which was transmitted from the origin "a," which is the first position, and delivered to the destination "e" or fifth position being the other channels also switched temporally. With the proposed model, it is possible to show the switching time in any order or need of transmission. Thus, the main objective of this model is considered reliable as a complement teaching of theoretical content applied in the classroom.

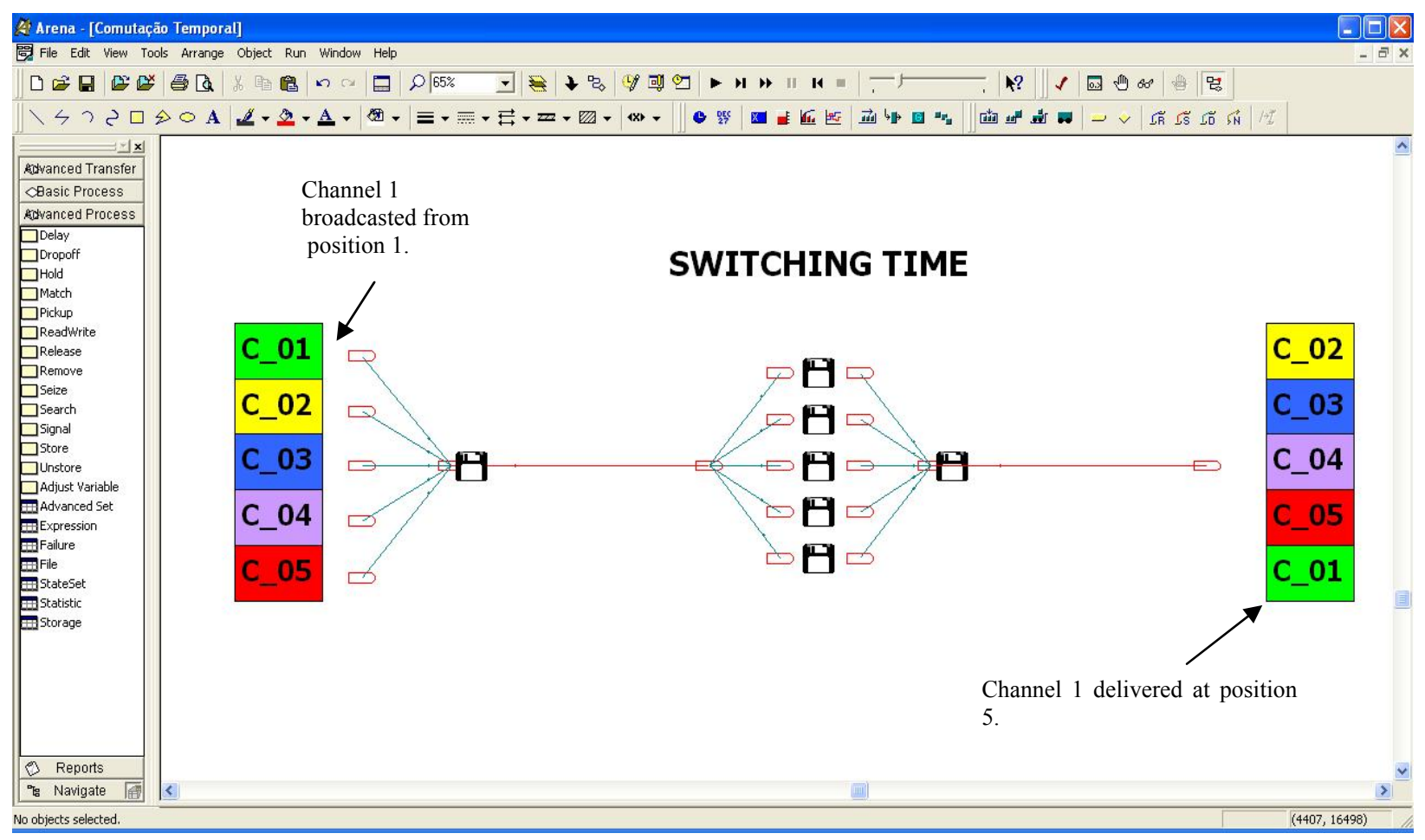

Figure 6: Temporal switch in ARENA animation

\subsection{Comparison of ARENA Models with Simulator of Telephony}

Table 3 shows a quick comparison between the animation models proposed and simulation software for digital telephony used in the course of telecommunications. 
Silva and Rangel

Table 3: Comparison of the standard simulator and the ARENA simulator

\begin{tabular}{llll}
\hline Characteristics & Digital telephony simulator & $\begin{array}{l}\text { Simulator } \\
\text { ARENA }\end{array}$ & proposed with \\
\hline Requirement & Needs CD ROM & ARENA \\
License & Yes & Free version \\
Interactive model & Yes & Yes \\
Permits change & No & Yes \\
Adjustment of view & No & Yes \\
\hline
\end{tabular}

It is worth mentioning that the models can be used outside of the classroom because it does not require the use of $\mathrm{CD}$ installation, requiring only the installation of the simulation software on the machines of the pupils for study purposes. This fact contributes positively to the learning process initially proposed with the development of didactical simulation models, encouraging the constant improvement of technical and technological training of the student.

\section{CONCLUSIONS}

The animation models developed for the discipline of digital telephony were adequate as a didactic complement in teaching the subjects offered. This happens because they can represent and dynamically display the static and theoretical approach that will be developed in the classroom.

The visualization tests helped to realize that the visual quality of the models is affected by the multimedia and/or computational resource used as support to the teacher and/or student, because the models are best viewed on devices that have wide screen. This conclusion is explained by the shape of the model built primarily to be distributed horizontally across the desktop of ARENA. Thus, the use of TVs or monitors with wider screens would provide more appropriate views.

The visualization test in the classroom with multimedia resource and standard TV sets was not satisfactory. That was due to the necessity of adjustments in the ARENA screen in the notebook used for the construction of the models, so that the animation would fit in the screen of the television set. This fact can be explained by the difference in the screen format between the computer that originated the animation and equipment used to view it in the classroom. After the adjustments made in the design of the model in the computer, it could be displayed properly on the television set. This setback would result in delay in the start of the class.

The visualization tests using computers with wide screen monitors were adequate and, similarly, one can conclude that the models are best viewed using television equipment with screen formats also wide screen. This is mainly due to the size of the model on the desktop of ARENA, as mentioned earlier.

Regarding the comparison made with the existing simulator, the construction of models of teaching using ARENA demonstrates, as a main advantage, the extracurricular use. For the existing model, it would be necessary each student to obtain a license to use, which is impractical. For the proposed models, it is only required to purchase the student version of the software simulator.

During the development of the three reported models, the potential of using discrete event simulation in the development of animation models for other segments of telecommunications was realized. Thus, the use of simulation software used for this work as a tool for construction of didactic models will contribute to the laboratory practices of various disciplines covered in the course of telecommunications and will add value to the student's professional training.

\section{ACKNOWLEDGEMENTS}

The authors thank the National Council for Scientific and Technological Development - CNPq and the Research Support Foundation of the State of Rio de Janeiro - FAPERJ for financial support for this research. They thank also to Maria Marta Garcia for suggestions to improve the text. 


\section{Silva and Rangel}

\section{REFERENCES}

Barradas, S., T. Pessoa, L. Lima, B. Tabet, and L. Marujo. 2010. "Simulação com Otimização de uma Rede de Telecomunicações de Acesso a Internet de Banda Larga." Anais do XLII Simpósio Brasileiro de Pesquisa Operacional, Bento Gonçalves.

Banks, J., J. S. Carson, B. L. Nelson, and D. M. Nicol. 2009. Discrete-Event System Simulation. 5th ed. New Jersey: Prentice-Hall, Inc.

Bernal, P. S. M., and C. Falbriard. 2002. Redes Banda Larga. 1st ed. São Paulo: Livros Érica.

Cardoso, P. A. 2006. "Interdisciplinaridade na Prática: A Experiência da Aplicação do Software Preactor como Ferramenta de Integração Curricular no Curso de Graduação em Engenharia de Produção."Anais do XXVI Encontro Nacional de Engenharia de Produção, Fortaleza.

Carson, J. S. 2004. "Introduction to Modeling and Simulation." In Proceedings of the 2004 Winter Simulation Conference, edited by R .G. Ingalls, M. D. Rossetti, J. S. Smith, and B. A. Peters, 9-16. Piscataway, New Jersey: Institute of Electrical and Electronics Engineers, Inc.

Goldsman, D. 2007. "A Simulation Course for High School Students." In Proceedings of the 2007 Winter Simulation Conference, edited by S. G. Henderson, B. Biller, M.-H. Hsieh, J. Shortle, J. D. Tew, and R. R. Barton, 2353-2356. Piscataway, New Jersey: Institute of Electrical and Electronic Engineers, Inc.

Kelton, D. W., R. P. Sadowski, and D. T. Sturrock. 2007. Simulation With Arena. 4th ed. Mc Graw Hill.

Kincaid, J. P., and K. K. Westerlund. 2009. "Simulation in Education and Traning." In Proceedings of the 2009 Winter Simulation Conference, edited by M. D. Rossetti, R. R. Hill, B. Johansson, A. Dunkin, and R. G. Ingalls, 273-280. Piscataway, New Jersey: Institute of Electrical and Electronic Engineers, Inc.

Montevechi, J. A. B., F. Leal, A. F. Pinho, R. F. da S. Costa, M. L. M. Oliveira, and A. L. F. da Silva. 2010. "Conceptual Modeling in Simulation Projects by Mean Adapted IDEF: An Application in a Brazilian Tech Company." In Proceedings of the 2010 Winter Simulation Conference, edited by B. Johansson, S. Jain, J. Montoya-Torres, J. Hugan, and E. Yücesan, 1624-1635. Piscataway, New Jersey: Institute of Electrical and Electronic Engineers, Inc.

Neto, V. S., and J. G. Neto. 2002. Telecomunicações: Redes de Alta Velocidade Sistemas PDH e SDH. 2nd ed. São Paulo: Livros Érica.

Nunes, A. F., and J. J. D. S. Rangel. 2009. "Uma Proposta de Documentação para Modelos Conceituais de Simulação em IDEF-SIM." Anais do XXIX Encontro Nacional de Engenharia de Produção, Salvador.

Pidd, M. 2004. Computer Simulation in Management Science. 5th ed. Chichester: John Wiley \& Sons Ltd., Inc.

Rangel, J. J. D. S., and A. C. T. Teixeira. 2010. "Utilização de Software Arena como Ferramenta de Simulação na Disciplina de Física no Ensino Médio." Anais do VI Encontro Mineiro de Engenharia de Produção, Coronel Fabriciano.

Silva, M. F. S., M. D. G. Pinto, and A. Subramanian. 2007. "Utilizando o Software Arena como Ferramenta de Apoio ao Ensino em Engenharia de Produção." Anais do XXVII Encontro Nacional de Engenharia de Produção, Foz do Iguaçu.

White Jr., K. P., and R. G. Ingalls. 2009. "Introduction to Simulation." In Proceedings of the 2009 Winter Simulation Conference, edited by M. D. Rossetti, R. R. Hill, B. Johansson, A. Dunkin, and R. G. Ingalls, 12-23. Piscataway, New Jersey: Institute of Electrical and Electronic Engineers, Inc.

\section{AUTHOR BIOGRAPHIES}

THIAGO MIRANDA PARAVIDINO DA SILVA is a teacher at Federal Fluminense Institute (IFF) and Masters student in Operation Research and Computational Intelligence at Candido Mendes University (UCAM). His e-mail address is thiagomps@iff.edu.br. 


\section{Silva and Rangel}

JOÃO JOSÉ DE ASSIS RANGEL is a professor at Federal Fluminense Institute (IFF) and Candido Mendes University (UCAM) in Campos dos Goytacazes, RJ - Brazil. He received a doctoral degree in Materials Engineering at UENF in 1998. His research interests include simulation of logistics and manufacturing, simulation of super hard materials process and simulation education. His e-mail address is joao@ucam-campos.br. 